\title{
Premilking Teat Preparation for Australian Pasture-Based Cows Milked by an Automated Milking System
}

\author{
K. L. Davis, ${ }^{\star 1}$ W. J. Fulkerson, ${ }^{*}$ S. C. Garcia, ${ }^{\star}$ D. Dickeson, ${ }^{*}$ and I. M. Barchia† \\ *University of Sydney, Camden, NSW 2570, Australia \\ †NSW Department of Primary Industries, Elizabeth Macarthur Agricultural Institute, Camden, NSW 2570, Australia
}

\begin{abstract}
Economic viability of automatic milking systems (AMS) within an Australian pasture-based farming system will be largely determined by the throughput (cows milked/h), which is the result of processes occurring while the cow is in the AMS milking crate. Premilking udder preparation is automated and optional on all AMS. Yet, very few conventional farms in Australia conduct premilking teat preparation regimens, with the majority (78\%) strategically washing only visibly dirty teats before milking cup attachment. The objective was to determine the impact of udder preparation in an AMS on the total time spent by cows in the AMS milking unit (crate time). An experiment was conducted with 80 lactating Holstein-Friesian cows in a crossover design over two 5wk periods to determine the effect of premilking teat preparation (no wash vs. wash) on milk yield, milk harvest rates, and total crate time per milking session in an AMS. Within this study there was no significant effect of treatment on quarter milk conductivity (no wash = 4,858 vs. wash $=4,829 \pm \mathrm{SE}=17 \mu \mathrm{S} / \mathrm{cm}$ ), milk blood concentration $($ no wash $=115.7$ vs. wash $=112.3 \pm 7.3$ $\mathrm{ppm}$ ) or test-day somatic cell counts (no wash $=2.044$ vs. wash $=2.039 \pm 0.025 \log _{10}$ SCC). There was similar total daily milk yield for the 2 treatments (no wash = 20.5 vs. wash $=20.1 \pm 0.2 \mathrm{~kg}$ of milk), but a greater mean quarter milk flow rate resulting from the wash treatment (no wash $=0.950$ vs. wash $=0.981 \pm 0.013 \mathrm{~kg}$ of milk/min). The faster milking was not sufficient to counter the time associated with washing, resulting in longer crate time (no wash $=6.02 \mathrm{vs}$. wash $=7.12 \pm 0.08$ $\mathrm{min} /$ milking session) and therefore, lower harvest rate (no wash $=2.08$ vs. wash $=1.74 \pm 0.02 \mathrm{~kg}$ of milk $/ \mathrm{min}$ crate time). Not washing teats would allow more efficient AMS utilization by potentially allowing more cows to be milked per machine, which would likely have a positive effect on the economic viability of this technology. The
\end{abstract}

Received August 26, 2007

Accepted March 5, 2008.

${ }^{1}$ Corresponding author: kendrad@usyd.edu.au results indicate that a longer term study, investigating the effect of washing teats on udder health and milk quality, is warranted.

Key words: dairy, automatic milking system, udder preparation, throughput

\section{INTRODUCTION}

Australian dairy farmers have increased the size of their operations to maintain or increase farm profitability as the unit cost of production increases (ABARE, 2006). Thus, the average land area of dairy farms increased by around $2 \%$, and the average number of cows milked per farm increased by about 58\% between 1994 1995 and 2003-2004. In addition, the milk yield per cow increased by around $8 \%$ resulting in an overall increase of $>80 \%$ in milk production per farm.

Labor accounted for 22 to $24 \%$ of operating costs on Australian dairy farms and it was the greatest cost after feed (D. Beca, Red Sky Agricultural Pty. Ltd., Warnambool, Victoria, Australia; personal communication). The amount of labor required for the milk harvesting process was the largest proportion (40 to 50\%) of total labor required for pasture-based dairy production (Mein and Smolenaars, 2001). A New Zealand study by Ohnstad and Jago (2007) reported that farmers estimated that milking accounted for 50 to $70 \%$ of all labor input on their largely pasture-based farms.

Apart from cost of labor, the production sector of the dairy industry suffers from an acute labor shortage (Dairy, 2006) and the sector is unlikely sustainable in the future if this shortage is not addressed (Garcia and Fulkerson, 2005). Clearly, the attractiveness of the dairy industry to, and the efficiency of, labor could improve if staff had the opportunity to work normal business hours, spend less time doing activities related to milking cows, and be more involved in farm management.

The economic viability of AMS would be greatly improved if the milk harvested per automatic milking unit could be increased (Lightfoot and Mulvany, 2002; Jago et al., 2006b), either through milking more cows or harvesting more milk/cow per day. Cow throughput in an automatic milking system (AMS) is limited by system 
features such as the time required for premilking udder preparation and cup attachment, physiological responses of the cow (milk let-down and milking-out rate), and cow behavior. Premilking teat cleaning in an AMS takes up to $90 \mathrm{~s}$ depending on the technology and the preparation regimen selected and therefore, affects throughput (potential cow milkings/h).

Premilking preparation of the teats is automated and optional on all AMS and is routine practice in the European Union (a requirement according to Council Directive 89/362/EEC). The preparation cleaned the teats, reduced the bacterial contamination of milk (Knappstein et al., 2004), and stimulated the udder and teats, inducing an oxytocin release that initiated milk ejection (Macuhova and Bruckmaier, 2000). There may be additional udder health benefits of an udder preparation routine as a result of reduced bacterial counts in milk and on teats (Galton et al., 1986).

The rationale for minimal teat-preparation procedures in Australia is that the udders of grazing cows remain relatively clean between milkings (Mein and Reinemann, 2007). Furthermore, Phillips (1986) suggested that selection by farmers against cows with high requirements for udder stimulation reduced the threshold value for triggering the milk ejection reflex. Clarke et al. (2004) indicated that there was still a milk let-down response to stimulation evident in Australian cows, but that the extra labor required for stimulation grossly exceeded the milking time saved. Dzidic et al. (2004) found strong milk let-down responses to a similar cleaning routine with Red Holstein/German Fleckvieh crossbred cows. They did not report the effect on total crate time, but cited Rothenganger et al. (1995), who suggested that although milking time was shortened when prestimulation was applied, total milking time was usually not reduced. Studies by Jago et al. (2006a) indicated improved milking speed, but an increase in total milking time by teat washing with a roller brush system (Fullwood AMS, Fullwood Ltd., Ellesmere, UK) for low-milking-frequency, New Zealand mixed-breed cows. Thus, we hypothesized that eliminating the time associated with premilking preparation in an AMS pasture-based system in Australia would reduce the total time spent by cows in the milking unit (crate time), without adversely affecting milk flow or total milk yield. A study involving $80 \mathrm{Hol}-$ stein-Friesian lactating cows was conducted to determine the effect of the premilking preparation on milking time for Australian pastured cows in an AMS.

\section{MATERIALS AND METHODS}

Ethics approval was granted through the Elizabeth Macarthur Agriculture Institute Animal Ethics Committee (Department of Primary Industries, New South
Wales, Australia; project number M04/07) before commencement of the project.

\section{Herd Management}

The automatic milking research farm at the Elizabeth Macarthur Agricultural Research Institute (Camden, New South Wales) was the site used. The farm had a total grazing area of $27.2 \mathrm{ha}$. The farm layout was such that the dairy was located at one end of the farm, and 6 blocks of pasture (range 1.38 to $6.57 \mathrm{ha}$ ) were accessed from a central dual lane. The dual lane allowed entry and exit traffic to and from the dairy. The dairy incorporated a waiting yard, 2 AMS, and a postmilking feed pad. All cows had free choice of being milked in 1 of 2 AMS [DeLaval voluntary milking system (VMS), DeLaval, Tumba, Sweden] and were fed during milking (18\% $\mathrm{CP}$ pelleted concentrate in the milking crate). Cows voluntarily moved around the system, bringing themselves from the pasture to the parlor, through the feed pad, and back to the pasture with milking parlor access available $24 \mathrm{~h} / \mathrm{d}$. From the pasture, cows walked along 1directional lanes (up to $1 \mathrm{~km}$ ) to a set of "smart gates" (automatic opening gates) situated approximately $50 \mathrm{~m}$ from the parlor, which would automatically open to the parlor if more than $5 \mathrm{~h}$ had lapsed since the previous milking, expected milk yield exceeded $10 \mathrm{~kg}$, or the previous milking was incomplete $(<70 \%$ of expected yield harvested from one or more quarters). If milking permission was denied, the cow was automatically sent back to the pasture at the smart gates. After milking, cows were either sent back to the pasture or allowed access to a feed pad, dependent on pasture available for grazing. A fresh area of pasture was made available at approximately 0700 and $1500 \mathrm{~h}$ each day. The diet comprised $41 \%$ perennial ryegrass-based pasture, $13 \%$ concentrate (commercial pellets in milking crates), and $46 \%$ partial mixed ration. The partial mixed ration consisted of $38 \%$ maize silage, $29 \%$ concentrate, $30 \%$ lucerne hay, and $2 \%$ soyabean pellets (\% of total DM content).

\section{Design}

A single crossover design was used. Eighty mixed-age Holstein-Friesian dairy cows were blocked by previous 7-d harvest rate ( $\mathrm{kg}$ of milk/min of crate time), milk yield/milking, milk yield/d, and stage of lactation, and assigned to treatment groups.

One group was assigned to no teat washing (NW) for the first trial period and a "medium" washing regimen for the second trial period, and vice versa for the teatwashing group (wash). Medium refers to the specific cleaning regimen chosen in the software supporting the DeLaval VMS units, which resulted in a cleaning period 
of 5.5 s/teat (VMSClient software, version 2006, DeLaval). Only cows that had been milking in the system for at least $2 \mathrm{wk}$ were included. All cows that calved into the herd or were dried off during the data collection period were excluded from the data set. The total herd size during the data collection periods (including nontrial cows) ranged from 107 to 120 cows.

The study was carried out over a 10 -wk period (early spring 2006) with a 1-wk lead-in period before each 4wk data collection period. Before the start date, all cows had experienced the udder preparation process consisting of a unique cleaning cup taken by the robotic arm around to each of the "to be milked" teats of an individual cow sequentially (blank and dry teats had been manually disabled for cleaning and milking). The teat was gently cleaned with warm water and air. The cleaning cup resulted in teats that were cleaned, premilked (foremilk was removed and discarded), and dried before milking. For the teat-washing treatment, the location of the teats was detected by laser and camera, as per milking cups. The cleaning process took approximately $1.25 \mathrm{~min}$ (depending on behavior and conformation of teats) and included $0.80 \mathrm{~min}$ of teat contact time, provided all 4 teats were located (includes cleaning and drying). After all "to be milked" teats were cleaned, the placement of milking cups proceeded.

\section{Measurements}

Milking frequency/period (total number of milkings/ cow), crate time ( $\mathrm{min} / \mathrm{milking}$ session; from the time the entry gate closed to the time that the gate opened allowing the cow to leave), yield ( $\mathrm{kg}$ of milk/milking session), milk harvest rate ( $\mathrm{kg}$ of milk/min of crate time), peak and mean teat milk flow rates ( $\mathrm{kg}$ of milk/min), milk conductivity/teat $(\mu \mathrm{S} / \mathrm{cm})$, proportion of expected yield harvested per teat (expected yield was automatically calculated based on production history and time since previous milking), and blood concentration per teat (ppm) were measured. All records were collected electronically by the VMS Client software.

The DeLaval VMS uses quarter meters that measure quarter yield, milk flow, conductivity, and blood. The conductivity meter was a basic technology that was used in many applications with one electrode emitting a defined current and another electrode receiving the current. How well the current is transferred in milk reflects the amount of available negative ions that can transfer electric current (mainly chloride). The units $(\mathrm{mS} / \mathrm{cm})$ are inversed resistance; thus, the greater the value, the lower the resistance for electric transfer in the milk. To measure blood, the meter exposed the milk cell to a specified wavelength and intensity that was received and analyzed for comparison to a calibrated color table.
Milk samples for analysis of milk fat, milk protein, and SCC were collected twice in each data collection period (at 14-d intervals in wk 2 and 4 of each period) over a 48-h period and results were converted to yield/ 24-h period. This conversion was a summed yield of each variable (milk fat and milk protein, within cow) divided by the sum of all the milking intervals leading to the sampled milkings (for each cow), which generated an average hourly production rate of milk fat and milk protein. These hourly production yields were multiplied by 24 to generate an average 24-h yield. The number of samples contributing to each data set was dependent on milking frequency; for example, a cow milking twice daily could have 3 to 5 samples contributing to her testday data depending on the timing of her milkings in relation to the actual sampling period because of the very nature of voluntary milking. Somatic cell count was presented as an average of all sampled milkings for each cow. Samples were analyzed for milk fat and milk protein concentrations using a Bentley B2000 (Bentley, Chaska, $\mathrm{MN}$ ) infrared analyzer (repeatability $<1.5 \% \mathrm{CV}$; accuracy $<5 \% \mathrm{CV}$ ) and SCC using a Bentley Somacount 300 (repeatability $<5 \% \mathrm{CV}$; accuracy 100,000 to $5,000,000$ within 10\%).

\section{Data and Statistical Analysis}

All variables were averaged for each cow and treatment. Cows were categorized as being in early (0 to 100 DIM, $\mathrm{n}=22$ ), mid (101 to 200 DIM, $\mathrm{n}=17$ ), or late $(>201$ DIM, $\mathrm{n}=41$ ) lactation on $\mathrm{d} 1$ of the first data collection period.

A linear mixed model was fitted to the data with treatment and stage of lactation as fixed terms and cow and milking station as random terms. The residual maximum likelihood (REML) estimation (Patterson and Thompson, 1971) was used to estimate the effect of all terms on the model. The $F$ statistic was calculated to determine significance between treatment effects. Least significant differences at $5 \%$ significance level were used to compare stage of lactation effects when the $F$ test showed significant results.

Herd test SCC data were log-transformed before analysis. A linear mixed model was fitted to the herd test data with treatment, stage of lactation, test day, and their interactions as fixed terms. Cow and cow by treatment interactions were included as random terms in the model. The REML estimation (Patterson and Thompson, 1971) was used to estimate the fixed and random effects and determine the statistical significance of each of the fixed terms. Least significant differences test at 5\% significance level was used to compare group differences for each significant $F$ statistic. 
Table 1. Treatment (no wash vs. wash) means and probabilities for treatment effect and treatment by stage of lactation interactions on milking frequency, milk yield, milking duration, and harvest rates

\begin{tabular}{lcrrc}
\hline Item $^{1}$ & No wash & Wash & $P$-value & $P$ interaction \\
\hline Milking frequency (milkings per cow per period) & $45.6 \pm 0.60$ & $45.7 \pm 0.60$ & 0.886 & 0.155 \\
Crate time per cow milking session (min) & $6.02 \pm 0.08$ & $7.12 \pm 0.08$ & $<0.001$ & 0.634 \\
Total yield per cow per milking session (kg) & $12.3 \pm 0.10$ & $12.1 \pm 0.10$ & 0.222 & 0.649 \\
Harvest rate (kg of milk harvested/min) & $2.08 \pm 0.02$ & $1.74 \pm 0.02$ & $<0.001$ & 0.899 \\
LF peak flow (kg of milk/min) & $1.43 \pm 0.01$ & $1.46 \pm 0.01$ & 0.075 & 0.337 \\
RF peak flow (kg of milk/min) & $1.37 \pm 0.01$ & $1.40 \pm 0.01$ & 0.022 & 0.124 \\
LR peak flow (kg of milk/min) & $1.58 \pm 0.01$ & $1.59 \pm 0.01$ & 0.912 & 0.879 \\
RR peak flow (kg of milk/min) & $1.57 \pm 0.01$ & $1.55 \pm 0.01$ & 0.124 & 0.024 \\
LF mean flow (kg of milk/min) & $0.97 \pm 0.01$ & $1.01 \pm 0.01$ & 0.019 & 0.672 \\
RF mean flow (kg of milk/min) & $0.93 \pm 0.01$ & $0.96 \pm 0.01$ & 0.004 & 0.296 \\
LR mean flow (kg of milk/min) & $1.07 \pm 0.01$ & $1.00 \pm 0.01$ & 0.063 & 0.973 \\
RR mean flow (kg of milk/min) & $1.07 \pm 0.01$ & $1.09 \pm 0.01$ & 0.122 & 0.173 \\
\hline
\end{tabular}

${ }^{1} \mathrm{LF}=$ left front, $\mathrm{RF}=$ right front, $\mathrm{LR}=$ left rear, $\mathrm{RR}=$ right rear quarters.

\section{RESULTS AND DISCUSSION}

Table 1 shows the effect of treatment and stage of lactation on crate time, milk yield/cow, harvest rate, and the quarter peak and mean milk flows.

Average crate time per milking session per cow was 1.10 min longer $(P<0.001)$ for the cows exposed to teat cleaning compared with not cleaning $(\mathrm{NW}=6.02$ vs. wash $=7.12 \pm \mathrm{SE}=0.08 \mathrm{~min}$ ). Given that the amount of time spent on the actual cleaning process was 1.25 min, there was a response in terms of milking speed, but this was not large enough to negate the extra crate time spent carrying out the teat cleaning process. A similar trend was reported by Dzidic et al. (2004) with a cleaning routine of $1.4 \mathrm{~min}$ and total main milking time being shorter for NW cows $(\mathrm{NW}=5.59$ vs. wash $=5.10$ $\mathrm{min})$. Thus, although total crate time was not reported, the reduction in main milking time was unlikely large enough to completely negate the time cost of the cleaning process with the Red Holstein/German Fleckvieh crossbred cows. Results from New Zealand (Jago et al., 2006a) using roller brushes to clean teats resulted in a total udder preparation time of $0.75 \mathrm{~min}$ with indications of some reduction in milking time, but an increase in total crate time for cows exposed to teat cleaning compared with no cleaning $(\mathrm{NW}=9.76$ vs. wash $=10.3 \mathrm{~min})$. This equates to a reduction of $0.21 \mathrm{~min}$ in machine on time as a result of udder stimulation vs. $0.15 \mathrm{~min}$ in this study. Nevertheless, the overall effect was greater in the present study because of the longer teat cleaning time and shorter crate time. The estimated time cost of premilking udder preparation was 110 min for every 100 milkings, equivalent to the time for 18 milkings for every 100 milkings by an AMS. Similar figures for the New Zealand work (with average milking intervals of $20 \mathrm{~h}$ ) indicated that the time saving of not brushing teats equated to an additional potential of 5 to 6 milkings for every 100 milkings (Jago et al., 2006a).
There was no significant effect of treatment on milk yield per milking session. The difference in crate time combined with the lack of difference in average yield resulted in a $19 \%$ greater $(P<0.001)$ milk harvest rate for the NW cows $(2.08 \pm 0.02 \mathrm{~kg}$ of milk/min) compared with the wash cows $(1.74 \pm 0.02 \mathrm{~kg}$ of milk $/ \mathrm{min})$.

There was no difference $(P>0.05)$ in average quarter peak milk flow rates from the rear quarters or the left front quarter, but there was a $2.3 \%$ lower peak flow rate $(P=0.022)$ from the right front quarter in the NW treatment (Table 1). This may be explained by the sequence of attachment. Generally, the rear milking teat cups were attached first, followed by the front milking teat cups. If the teat contact time resulting from the medium washing regimen was insufficient to elicit a complete physical stimulation-induced milk ejection, then it is possible that the washing regimen plus the contact of the rear milking cups resulted in greater peak milk flow rates for the front teats (only significant for the left front teat due to the lower variance within the data). The NW cows had 3.2\% lower average quarter mean milk flow rates from the front quarters $(P<0.05)$, indicating that the washing treatment did have an effect on milking speed of the front quarters, but not the rear quarters. This finding supports that of Clarke et al. (2004) that Australian cows do respond to stimulation; however, the effect, although significant, was small, resulting in only a 5\% improvement in milk flow with no effect on milk yield/cow. It is possible that the long-term effects of the reduced peak and mean milk flow rate of the front quarters may result in an overall decreased milk production from the front quarters, supporting the need for a longer term study on the effects of teat washing.

The proportion of the expected yield harvested at each milking was greater for the NW right front quarter $(P=$ 0.042 ; Table 2). It is possible that the difference was due to the removal of very small volumes of milk (10 to 20 
Table 2. Treatment (no wash vs. wash) means and probabilities for treatment effects and treatment by stage of lactation interactions on individual quarter milk harvested (proportion of expected yield), conductivity level, and milk blood concentration

\begin{tabular}{lcccc}
\hline Item $^{1}$ & No wash & Wash & $P$-value & $P$ interaction \\
\hline LF \% expected yield harvested & $98.1 \pm 0.19$ & $97.7 \pm 0.19$ & 0.123 & 0.345 \\
RF \% expected yield harvested & $99.1 \pm 0.22$ & $98.5 \pm 0.22$ & 0.042 & 0.209 \\
LR \% expected yield harvested & $98.9 \pm 0.22$ & $98.5 \pm 0.22$ & 0.200 & 0.743 \\
RR \% expected yield harvested & $96.7 \pm 0.23$ & $96.2 \pm 0.23$ & 0.074 & 0.760 \\
LF conductivity $(\mu \mathrm{S} / \mathrm{cm})$ & $4,879 \pm 17$ & $4,842 \pm 17$ & 0.091 & 0.091 \\
RF conductivity $(\mu \mathrm{S} / \mathrm{cm})$ & $4,858 \pm 19$ & $4,820 \pm 19$ & 0.135 & 0.011 \\
LR conductivity $(\mu \mathrm{S} / \mathrm{cm})$ & $4,848 \pm 16$ & $4,821 \pm 16$ & 0.199 & 0.223 \\
RR conductivity $(\mu \mathrm{S} / \mathrm{cm})$ & $4,845 \pm 17$ & $4,832 \pm 17$ & 0.569 & 0.358 \\
LF Milk blood concentration & $188.3 \pm 8.0$ & $189.6 \pm 8.0$ & 0.902 & 0.210 \\
RF Milk blood concentration & $90.0 \pm 6.1$ & $89.5 \pm 6.1$ & 0.864 & 0.440 \\
LR Milk blood concentration & $85.2 \pm 7.5$ & $84.0 \pm 7.5$ & 0.906 & 0.456 \\
RR Milk blood concentration & $98.4 \pm 7.6$ & $86.0 \pm 7.6$ & 0.217 & 0.387 \\
\hline
\end{tabular}

${ }^{1} \mathrm{LF}=$ left front, $\mathrm{RF}=$ right front, $\mathrm{LR}=$ left rear, $\mathrm{RR}=$ right rear quarters.

$\mathrm{mL}$ of milk/quarter) from the washed quarters during the udder preparation process.

There was no treatment effect on quarter conductivity or milk blood concentration (Table 2) and it was unlikely that the lack of washing resulted in a decrease in udder health over the period of data collection. Nonetheless, the duration and design of this investigation were not appropriate for the determination of long-term treatment effects on udder health. The results presented here are promising enough to encourage further investigation into the long-term effects of udder preparation on milk production, udder health, and milk quality.

There was a stage of lactation by treatment interaction $(P=0.024)$ on the right rear peak milk flow with the late-lactation NW cows having a $2.7 \%$ greater flow (NW = $1.47 \mathrm{vs}$. wash $=1.43 \pm 0.016 \mathrm{~kg}$ of $\mathrm{milk} / \mathrm{min})$. There was no difference for the early $(\mathrm{NW}=1.72 \mathrm{vs}$. wash $=1.75$ $\pm 0.016 \mathrm{~kg}$ of $\mathrm{milk} / \mathrm{min}$ ) or mid lactation $(\mathrm{NW}=1.61 \mathrm{vs}$. wash $=1.57 \pm 0.016 \mathrm{~kg}$ of $\mathrm{milk} / \mathrm{min}$ ) cows. There was no treatment by stage of lactation interactions $(P>0.05)$ on any of the other variables measured in this investigation. The lack of other interactions suggests there would be no reason to target the wash vs. NW regimen to a particular stage of lactation.

There was no effect $(P>0.05)$ of treatment on $\log (\mathrm{SCC})$ (2.044 vs. $2.039 \pm 0.025$ for NW and wash, respectively), test-day average milk yield (7-d average), milk fat content, or milk protein content (Table 3). The stage of lactation effects on SCC $(P=0.002)$, average milk yield $(P<0.001)$, and milk protein contents $(P<0.001)$ were expected. The test-day effect on average milk yield $(P<$ $0.001)$ and fat percentage $(P<0.001)$ was not unexpected because of the variability of feed quality associated with a typical grazing system. There was a significant treatment by stage of lactation interaction $(P=0.002)$ for $\log$ (SCC), with the difference occurring in the early-lactation animals with animals subjected to the wash treat- ment having a greater mean $\mathrm{SCC}(\mathrm{NW}=1.690 \pm 0.072$ vs. wash $=1.837 \pm 0.079$ in $\log _{10}$ scale. For mid lactation, $\log _{10}$ (SCC) was $2.092 \pm 0.084$ vs. $2.004 \pm 0.082$ and the late-lactation $\log _{10}(\mathrm{SCC})$ was $2.214 \pm 0.052$ vs. $2.152 \pm$ 0.053 , respectively.

It is acknowledged that this short-term study was carried out during a period when environmental conditions were favorable, resulting in the majority of cows entering the dairy with clean, dry teats. The results reported would likely vary with season and environmental conditions. Given that the AMS is technologically incapable of differentiating between clean and dirty teats it would be recommended that when environmental conditions are such that some cows are entering the dairy with visibly dirty teats, a teat-washing regimen needs implementation to ensure that milk quality and udder health are not compromised. The results may provide justification for externalizing the teat-washing routine by having an udder preparation system outside of the milking crate, thereby increasing throughput. Some farms in Australia have in-ground water sprayers in the concrete holding areas that wash the underside of the cows in the first of 2 holding pens allowing time for drip drying before milking. Such a system is not as targeted or as accurate as the sophisticated teat cleaning system investigated in this study, but may be sufficient to negate any negative effects of a no-wash system.

\section{CONCLUSIONS}

The results suggest that there is insufficient physiological response from Australian dairy cows in a pasturebased AMS system to warrant teat washing as a tool to promote the milk let-down response to induce faster milking. This study was not designed to investigate the effects of washing vs. no washing on udder health or milk quality. The data presented as indicators of udder 
Table 3. Treatment (no wash vs. wash) means and probabilities for treatment effect and all the fixed terms fitted in the model on log SCC, test-day milk yield, and milk fat and protein concentrations

\begin{tabular}{|c|c|c|c|c|c|}
\hline Treatment & Log (SCC) & $\begin{array}{l}\text { Retransformed } \\
\text { SCC }(\times 1,000)\end{array}$ & $\begin{array}{l}\text { Milk yield, } \\
\text { kg/cow }\end{array}$ & Milk fat, \% & Milk protein, \% \\
\hline No wash & $2.04 \pm 0.025$ & 110.7 & $20.46 \pm 0.19$ & $3.87 \pm 0.059$ & $3.40 \pm 0.016$ \\
\hline Wash & $2.04 \pm 0.025$ & 109.4 & $20.14 \pm 0.19$ & $3.84 \pm 0.059$ & $3.40 \pm 0.016$ \\
\hline $\mathrm{LSD}^{1}$ & 0.070 & & 0.05 & 0.168 & 0.044 \\
\hline Treatment & 0.997 & & 0.0619 & 0.814 & 0.680 \\
\hline Lact $^{2}$ & 0.002 & & $<0.001$ & 0.123 & $<0.001$ \\
\hline Day $^{3}$ & 0.247 & & $<0.001$ & $<0.001$ & 0.072 \\
\hline Treatment $\times$ Lact & 0.002 & & 0.604 & 0.898 & 0.829 \\
\hline Treatment × Day & 0.742 & & 0.873 & 0.538 & 0.947 \\
\hline Lact $\times$ Day & 0.548 & & 0.955 & 0.144 & 0.681 \\
\hline Tratment $\times$ Lact $\times$ Day & 0.991 & & 0.011 & 0.031 & 0.340 \\
\hline
\end{tabular}

hygiene must be interpreted with caution because of the trial design and the short duration of the investigation. Yet the data presented warrant further investigation into udder preparation and the effect on udder health, milk quality, and longer term production. This study was carried out during a period when environmental conditions were favorable and further investigation needs to challenge the results in different environmental and seasonal conditions. There was no difference in milking frequency within this trial, but the potential time saving associated with NW could allow for more cows milked per machine. Through its effect on potential cow to milking station ratios, this could affect the economic viability of this technology in Australian dairy systems.

\section{ACKNOWLEDGMENTS}

The authors wish to acknowledge the assistance of Terry Osborne and Shannon Bennetts. We wish to acknowledge the support of all sponsors of the FutureDairy project, particularly Dairy Australia, NSW Department of Primary Industries, University of Sydney, and DeLaval.

\section{REFERENCES}

ABARE. 2006. Production Systems, Productivity and Profit. Australian Dairy 06.1, Canberra, Australia.

Clarke, T., E. M. Cuthertson, R. K. Greenall, M. C. Hannah, E. Jongman, and D. Shoesmith. 2004. Milking regimes to shorten milking duration. J. Dairy Res. 71:419-426.

Dairy 2006. 2006. Situation and Outlook: Report to the Australian Dairy Industry, June 2006, Dairy Australia, Melbourne, Australia.

Dzidic, A., J. Macuhova, and R. M. Bruckmaier. 2004. Effects of cleaning duration and water temperature on oxytocin release and milk removal in an automatic milking system. J. Dairy Sci. 87:41634169 .
Galton, D. M., L. G. Petersson, and W. G. Merrill. 1986. Effects of premilking udder preparation practices on bacterial counts in milk and on teats. J. Dairy Sci. 69:260-266.

Garcia, S. C., and W. J. Fulkerson. 2005. Opportunities for future Australian dairy systems: A review. Aust. J. Exp. Agric. 45:1041-1055

Jago, J. G., K. L. Davis, P. C. Copeman, and M. W. Woolford. 2006a. The effect of pre-milking teat-brushing on milk processing time in an automated milking system. J. Dairy Res. 72:187-192.

Jago, J. G., K. L. Davis, M. Newman, and M. W. Woolford. 2006b. An economic evaluation of automatic milking systems for New Zealand dairy farms. Proc. N.Z. Soc. Anim. Prod. 66:263-269.

Knappstein, K., N. Roth, H.-G. Walte, J. Reichmuth, B. A. Slaghuis, R. T. Ferwerda-van Zonneveld, and A. Mooiweer. 2004. Effectiveness of automatic cleaning of udder and teats and effects of hygiene management. Report on effectiveness of cleaning procedures applied in different automatic milking systems. EU Report: www.automaticmilking.nl

Lightfoot, C., and J. Mulvany. 2002. Farming Systems for Automatic Milking in Australia. Occasional report prepared for Dairy Australia, Melbourne, Australia.

Macuhova, J., and R. M. Bruckmaier. 2000. Oxytocin release, milk ejection and milk removal in the Leonardo multi-box automatic milking system. Pages 134-185 in Proc. Int. Symp. Robotic Milking, Lelystad, the Netherlands. H. Hogeveen, and A. Meijering, ed. Wageningen Acad. Publ., Wageningen, the Netherlands.

Mein, G., and F. Smolenaars. 2001. Making the most of the milk harvest. A prospectus for the milk quality and harvesting program. Dairy Research and Development Corporation, Melbourne, Victoria, Australia.

Mein, G. A., and D. J. Reinemann. 2007. Making the most of machineon time: What happens when the cups are on? In Proc. 2007 Mtg. Natl. Mastitis Counc. National Mastitis Council, Madison, WI.

Ohnstad, I., and J. Jago. 2007. The development of automatic cup attachment technology for New Zealand dairy farms-A feasibility study. Report to Dairy InSight, Wellington, New Zealand.

Patterson, H. D., and R. Thompson. 1971. Recovery interblock information when block sizes are unequal. Biometrika 31:100-109.

Phillips, D. S. M. 1986. Studies on pre-milking preparation. 8. A comparison of 10 and 45 seconds of wash and stimulus. N.Z. J. Agric. Res. 29:667-672.

Rothenganger, E., R. M. Bruckmaier, and J. W. Blum. 1995. Association and dissociation of single quarter and total milk flow in dairy cows: Effects of milking with and without pre-stimulation. Milchwissenschaft 50:63-66. (Cited in Dzidic et al., 2004.) 